\title{
The Use of Artificially Intelligent Self-Diagnosing Digital Platforms by the General Public: Scoping Review
}

Stephanie Aboueid ${ }^{1}$, MSc, RD; Rebecca H Liu ${ }^{2}$, MSc, PhD; Binyam Negussie Desta ${ }^{1}$, MPH; Ashok Chaurasia ${ }^{1}, \mathrm{PhD}$; Shanil Ebrahim ${ }^{3,4}, \mathrm{PhD}$

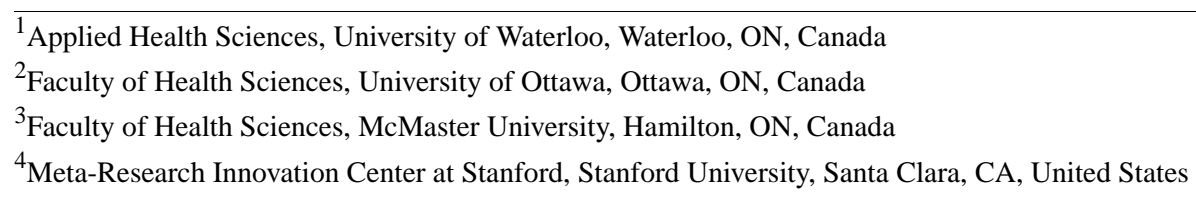

Corresponding Author:

Stephanie Aboueid, MSc, RD

Applied Health Sciences

University of Waterloo

200 University Avenue West

Waterloo, ON, N2L 3G5

Canada

Phone: 16134061899

Email: seaboueid@uwaterloo.ca

\section{Abstract}

Background: Self-diagnosis is the process of diagnosing or identifying a medical condition in oneself. Artificially intelligent digital platforms for self-diagnosis are becoming widely available and are used by the general public; however, little is known about the body of knowledge surrounding this technology.

Objective: The objectives of this scoping review were to (1) systematically map the extent and nature of the literature and topic areas pertaining to digital platforms that use computerized algorithms to provide users with a list of potential diagnoses and (2) identify key knowledge gaps.

Methods: The following databases were searched: PubMed (Medline), Scopus, Association for Computing Machinery Digital Library, Institute of Electrical and Electronics Engineers, Google Scholar, Open Grey, and ProQuest Dissertations and Theses. The search strategy was developed and refined with the assistance of a librarian and consisted of 3 main concepts: (1) self-diagnosis; (2) digital platforms; and (3) public or patients. The search generated 2536 articles from which 217 were duplicates. Following the Tricco et al 2018 checklist, 2 researchers screened the titles and abstracts $(n=2316)$ and full texts ( $n=104)$, independently. A total of 19 articles were included for review, and data were retrieved following a data-charting form that was pretested by the research team.

Results: The included articles were mainly conducted in the United States $(n=10)$ or the United Kingdom ( $n=4)$. Among the articles, topic areas included accuracy or correspondence with a doctor's diagnosis $(n=6)$, commentaries $(n=2)$, regulation $(n=3)$, sociological $(n=2)$, user experience $(n=2)$, theoretical $(n=1)$, privacy and security $(n=1)$, ethical $(n=1)$, and design $(n=1)$. Individuals who do not have access to health care and perceive to have a stigmatizing condition are more likely to use this technology. The accuracy of this technology varied substantially based on the disease examined and platform used. Women and those with higher education were more likely to choose the right diagnosis out of the potential list of diagnoses. Regulation of this technology is lacking in most parts of the world; however, they are currently under development.

Conclusions: There are prominent research gaps in the literature surrounding the use of artificially intelligent self-diagnosing digital platforms. Given the variety of digital platforms and the wide array of diseases they cover, measuring accuracy is cumbersome. More research is needed to understand the user experience and inform regulations.

(JMIR Med Inform 2019;7(2):e13445) doi: 10.2196/13445

\section{KEYWORDS}

diagnosis; artificial intelligence; symptom checkers; diagnostic self evaluation; self-care 


\section{Introduction}

\section{Background}

Researching health information on the internet has become common practice by the general public [1-3]. Those who do not have access to health care services are more likely to use the internet for health information [4]. In some cases, browsing the internet for health information can have certain benefits such as improving health outcomes by increasing the availability of information, providing social support, and improving self-efficacy $[5,6]$. However, potential negative consequences still exist; the information may not be reliable, and the individual seeking information may have low health literacy [6]. For example, an individual may not be able to critically analyze the health information and assess the applicability of the information to their case, which could result in detrimental effects on their health [6]. Therefore, health information widely circulated on the internet should be interpreted with caution [7].

Significant technological advances have resulted in the rise of more sophisticated digital health platforms, which could potentially mitigate this issue, especially those involving artificial intelligence (AI). Interest in AI appears to be relatively recent; however, the term dates back to the 1950s and is described as the theory and development of computer systems that can perform tasks that would normally require human intelligence [8,9]. Notably, AI has become incorporated in computerized diagnostic decision support systems, which were initially developed for health professionals. These platforms have now become readily available to the general public and are known as self-diagnosing apps or symptom checkers, which include the Mayo Clinic symptom checker, Babylon Health, the Ada health app, and the K Health app. On the basis of the medical information and symptoms provided by an individual, these digital platforms perform 2 main functions: (1) provide individuals with a list of potential diagnoses and (2) assist with triage [10]. While the accuracy of symptom checkers is still under question $[11,12]$, this technology has been gaining traction globally $[13,14]$ owing to its potential in addressing the lack of access to primary care providers (PCPs) and unnecessary medical visits - prominent issues in Canada and most parts of the world [15-18].

\section{Objectives}

Although accuracy is important to consider, it is of equal importance to understand the overall body of knowledge that surrounds this technology, including legal and ethical implications and user experiences. In light of this, it is imperative to systematically map the literature available on artificially intelligent self-diagnosing digital platforms to identify the areas of research pertaining to this topic and to outline the key gaps in knowledge. This information can support the growing interest in leveraging AI technology in health care systems. As such, this scoping review aimed to answer the following question: What is known about the use of artificially intelligent self-diagnosing digital platforms by the general public and what are the main knowledge gaps in the literature?

\section{Methods}

\section{Eligibility Criteria}

In this review, self-diagnosing digital platforms were defined as platforms that utilize algorithms to provide a list of potential diagnoses to the user based on the medical information and symptoms provided. Although this scoping review does not entail quality assessment, it follows a sound methodological approach to map out the results in a concise manner for knowledge users. This scoping review follows the 2018 checklist developed by Tricco et al [19] for reporting scoping reviews. Ethics approval was not required.

The 3 main overarching concepts that guided this search were (1) self-diagnosis; (2) digital platforms; and (3) public or patients. Given the relatively new emergence of this technology and its use by the general public, the search was not limited by a publication date. Articles that were included in the review were those that (1) pertained to the use of self-diagnosing digital platforms by the lay public or patients and (2) were written in English or French. Exclusion criteria were articles that (1) focused on the use of self-diagnosing AI technology by health professionals; (2) described the back-end development of a self-diagnosing platform (eg, neural networks and architecture); (3) focused on digital health platforms that provide general health information, advice for disease management or triage; (4) focused on a tool that entails a validated questionnaire rather than an algorithm; and/or (5) examined test kits or digital platforms requiring an image upload. To allow for a wide array of results to be included, quantitative, qualitative, and mixed-methods studies or reports were eligible for inclusion.

\section{Information Sources and Search}

This scoping review systematically searched citation databases and the gray literature for relevant published and unpublished articles. The citation databases included PubMed (Medline), Scopus, Association for Computing Machinery Digital Library, Institute of Electrical and Electronics Engineers, and Google Scholar. To supplement the gray literature retrieved through Google Scholar [20], OpenGrey and ProQuest Dissertations and Theses were also searched. The final search strategy for each data source was defined and refined with the assistance of a librarian (Rebecca Hutchinson, University of Waterloo) and was finalized on November 19, 2018. The final search strategy for PubMed (Medline) can be found in Multimedia Appendix 1. The final search results were exported into RefWorks for screening.

\section{Selection of Sources of Evidence}

Once duplicates were removed in RefWorks, the screening process was conducted independently by 2 researchers (SA and RHL). The decision tree in Figure 1 was used as a guide to screen titles and abstracts (or executive summaries for reports and commentaries). Articles that were extracted from the title and abstract screening stage were read in their entirety (full-text review). For the full-text screening step, 2 researchers (SA and RHL) screened the same 30 articles to assess inter-rater reliability. Any uncertainty and disagreements were discussed and resolved through consensus. Following full-text review, 
the reference lists of eligible articles were systematically screened. Similarly, for any review paper screened at the full-text review stage, references were screened for potentially relevant articles meeting the inclusion criteria.

Figure 1. Decision tree for assessing article eligibility.

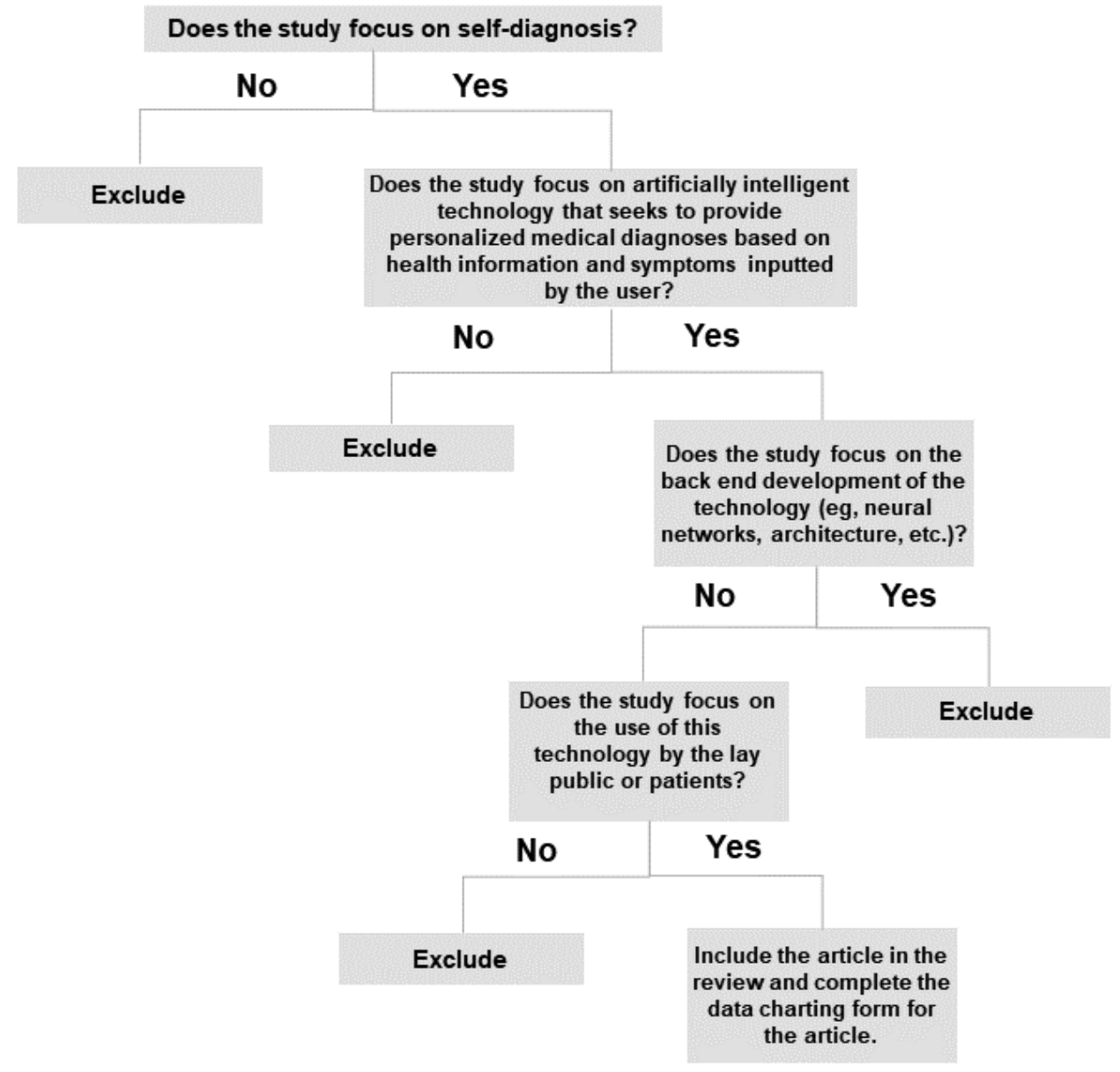

\section{Data Charting Process}

Once the final number of articles was determined, a scan through these articles allowed the research team to gain a high-level understanding of the topics of interest in which self-diagnosing digital platforms were being examined (eg, accuracy and regulatory concerns). This allowed for the development of a data-charting form that captured all the relevant information, irrespective of the article type (eg, clinical trial or a qualitative study on user experience). The data-charting form was pretested with the same 5 articles to assess consistency. No changes were made to the form following this exercise.

\section{Data Extraction}

The variables collected through the data-charting form included the following: country, year of publication, main objective, the main area of study (eg, clinical, legal, and ethical), study design, data sources used (if any), target population (if any), sample size and sample characteristics (if any), methods/statistical analyses (if applicable), main findings, and study limitations (if applicable).

\section{Synthesis of Results}

Scoping reviews provide knowledge users with a concise overview on the literature available on a given topic of interest
[21]. Given the heterogeneity of the studies included in this review, studies were grouped based on a specific area of study. A concept map was used to illustrate the breadth of studies surrounding self-diagnosing AI technology. Tables were used to provide an overview on the types of articles found in the literature and the data extracted from each article. A thematic synthesis was used to outline the knowledge gaps in the literature and other key considerations.

\section{Results}

\section{Selection of Sources of Evidence}

Figure 2 depicts the flow chart, which illustrates the selection process at each screening step. Our search identified a total of 2536 from which 217 were duplicates. In addition, 2 researchers independently screened the titles and abstracts of 2316 articles from which 2229 were excluded based on relevance and eligibility criteria. A total of 104 full-text articles were retrieved and assessed for eligibility. Of these, 76 articles were excluded for the following reasons: described the back-end development of the digital platform or the algorithm, examined the use of digitized questionnaires rather than algorithm-based digital platforms, the digital platform required the input of health professionals, provided the risk of disease, monitored symptoms, 
technology designed for health professionals, not in scope, and did not provide enough data or information. We excluded 12 additional articles because we were unable to retrieve them. Through reference screening of the included articles, we identified 17 potentially relevant articles from which 3 articles were included in the review. A total of 19 articles were considered eligible for this review. Inter-rater reliability was assessed at the full-text stage which resulted in a score of 0.82 , an almost perfect agreement score, between the 2 reviewers (SA and RHL) [22,23].

Figure 2. Preferred Reporting Items for Systematic Reviews and Meta-Analyses flowchart of included articles. ACM DL: Association for Computing Machinery Digital Library; IEEE: Institute of Electrical and Electronics Engineers.

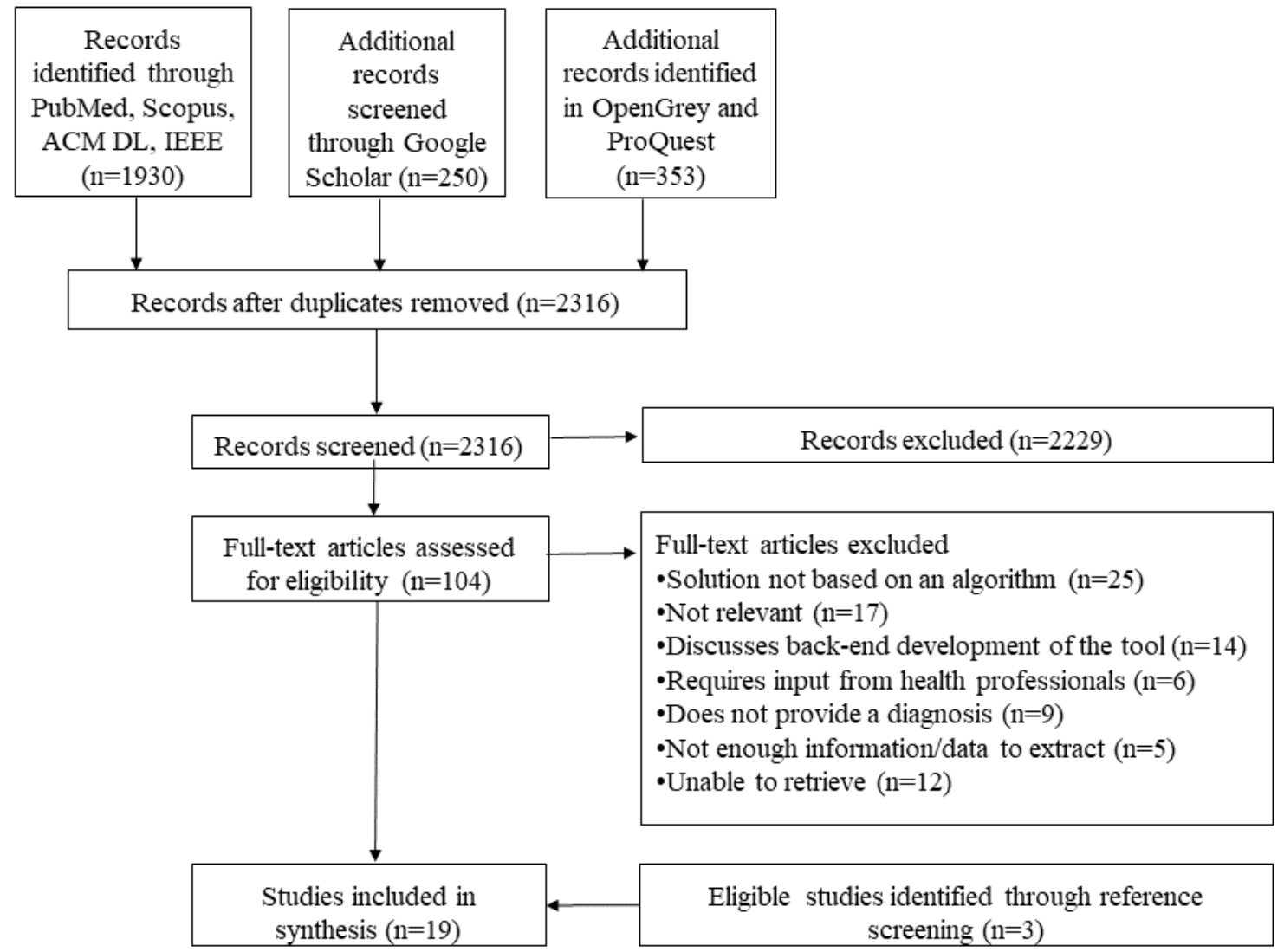

\section{Characteristics of Sources of Evidence}

The concept map in Figure 3 provides an illustrative overview of the main topic areas surrounding the use of artificially intelligent self-diagnosing digital platforms by the general public. The articles were mainly conducted in the United States $(n=10)$ or the United Kingdom $(n=4)$. In total, 2 of the articles were commentaries and the rest focused on the following areas: accuracy or correspondence with a doctor's diagnosis, regulation, sociological perspectives, experience, theory, privacy and security, ethics, and design. The concept map also outlines the main themes that emerged from the articles and the health conditions examined. 
Figure 3. Concept map of the literature surrounding the use of artificially intelligent self-diagnosing digital platforms by the general public. DCM: degenerative cervical myelopathy; ENT: ear, nose, and throat; FDA: Food and Drug Administration; HIPAA: Health Insurance Portability and Accountability Act; NHS: National Health Service.

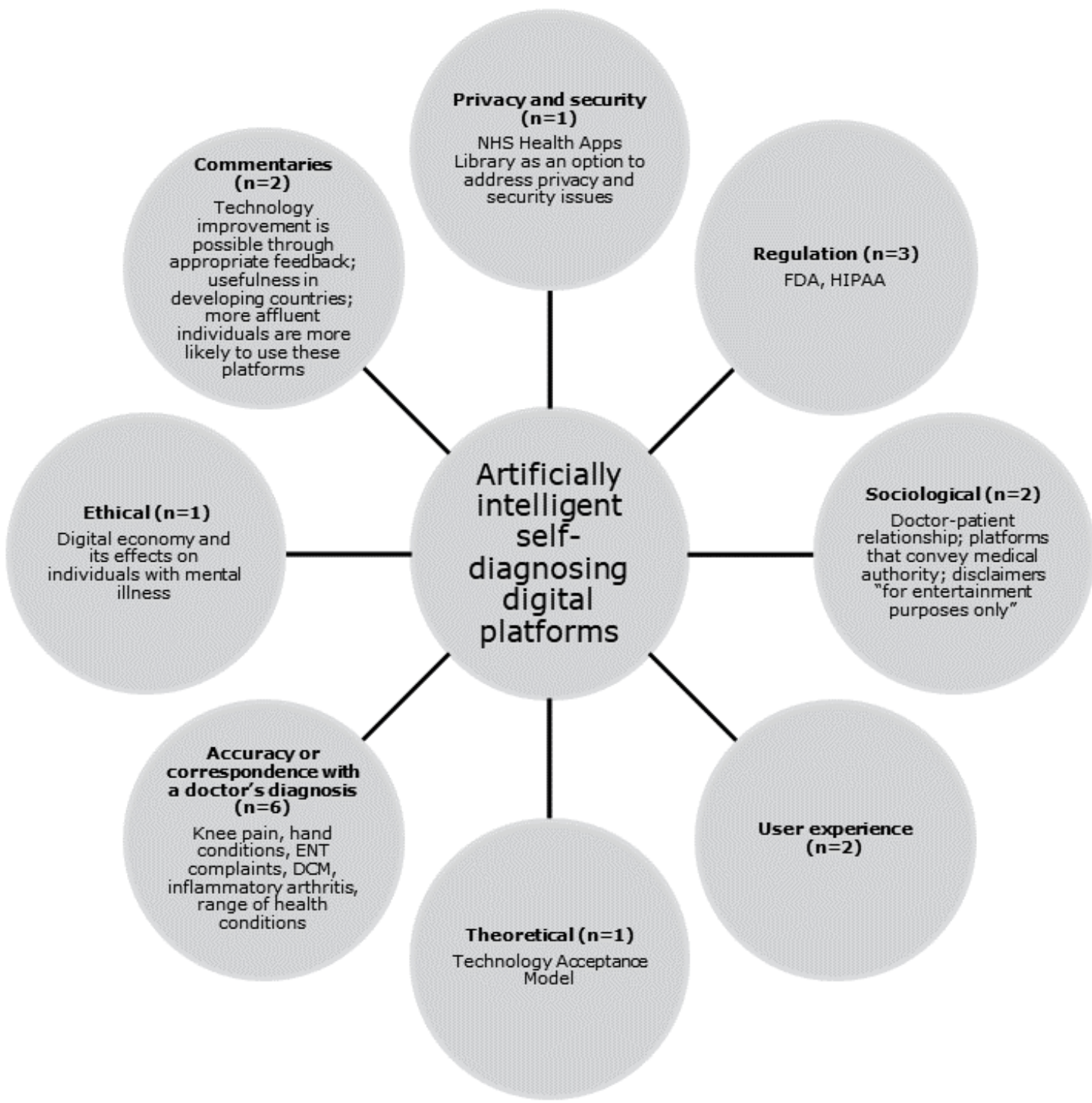

\section{Results of Individual Sources of Evidence}

Multimedia Appendix 2 provides an overview of all included articles and outlines the following variables: the article type, topic area examined, main objective, and main findings [24-42].

\section{Synthesis of Results}

Table 1 provides additional information on studies that entailed participant recruitment to answer their research question. These articles tended to focus on accuracy of the digital platform or user experience. 
Table 1. Synthesis of results of studies with participants.

\begin{tabular}{|c|c|c|c|c|c|}
\hline $\begin{array}{l}\text { First author, year, } \\
\text { reference, country }\end{array}$ & $\begin{array}{l}\text { Sample size } \\
\text { (n) }\end{array}$ & Target population & Data collection & $\begin{array}{l}\text { Digital platforms } \\
\text { used }\end{array}$ & Methods \\
\hline $\begin{array}{l}\text { Bisson, } 2014 \text { [26], } \\
\text { United States }\end{array}$ & 572 & Individuals with knee pain & $\begin{array}{l}\text { Primary data collection from } \\
\text { patients and electronic med- } \\
\text { ical records (EMRs) }\end{array}$ & $\begin{array}{l}\text { A Web-based pro- } \\
\text { gram developed by } \\
\text { the research team }\end{array}$ & $\begin{array}{l}\text { Sensitivity and specificity of } \\
\text { the program's ability to pro- } \\
\text { vide a correct diagnosis for } \\
\text { knee pain was tested, out of } \\
\text { a possible } 21 \text { conditions in } \\
\text { which the algorithm was } \\
\text { trained to diagnose }\end{array}$ \\
\hline
\end{tabular}

Bisson, 2016 [27], 328

United States

Copeland, 2018

[29], United States

Farmer, 2011 [32], United Kingdom

Hageman, $2014 \quad 86$

[33], United States

86

Lanseng, 2007 [36], 160 Norway

Luger, 2014 [37], 79

United States

Powley, 2016 [40], 34 United Kingdom
Individuals with knee pain

Primary data collection from patients and EMRs

Users who tested the proto- Primary data collection uscol (specifics not provided) ing the System Usability Scale and the Usability Metric for User Experience

Patients coming in to the Ear, Nose, Throat surgeon's office

Patients coming in to an outpatient hand and upper extremity surgeon's office

Individuals between the ages of 18 and 65 years

Older adults (aged 50 years or older)
Primary data collected from patients over 1 month

Primary data collection from patients and physicians
Primary data collection using the Technology Readiness Survey (TRI)

Primary data collection of think-aloud protocols
A Web-based program developed by the research team

Prototype developed Descriptive statistics by the research team

Boots WebMD

Symptom

WebMD Symptom

Checker
WebMD Symptom Checker
$\mathrm{N} / \mathrm{A}^{\mathrm{a}}$

Cher

Sensitivity and specificity were calculated

Not provided was used to determine the level of correspondence of the provided diagnosis by the diagnostic application physician

A survey with an internet based medical self - diagnosis application as the focal technology was conducted; The research hypotheses up with a questionnaire 2 vignettes that depicted

The Pearson chi-square test and the final diagnosis of the were tested by completing a scenario and then following-

Participants received one of symptoms of illness. Participants talked out loud about their thoughts and actions while attempting to diagnose the symptoms with and without the help of common internet tools (Google and WebMD's Symptom Checker); Think-aloud content of participants was then compared with those who were accurate in their diagnosis versus those who were not.

Consecutive patients with newly presenting clinically apparent synovitis or a new onset of symptoms consistent with inflammatory arthritis
Primary data collection from National Health Serpatients vice (NHS) and WebMD Symptom Checkers
Patients were asked questions about their internet use in relation to their presenting symptoms. Subsequently, they completed the NHS and the WebMD symptom checkers and their answers as well as outcomes were recorded.

${ }^{\mathrm{a}}$ Not applicable. 


\section{Discussion}

\section{Summary of Evidence and Knowledge Gaps}

In this scoping review, 19 articles were included that examined artificially intelligent self-diagnosing digital platforms from various perspectives. Despite the popularity and accessibility of self-diagnosing AI technology by the public, it is noteworthy that research examining the accuracy of these platforms is limited. As such, it is unclear whether these platforms hinder or improve the health of users. Although some argue that the use of this technology may cause an individual to delay seeking care, it is important to recognize that delayed diagnoses are prevalent even without the use of this technology $[40,42,43]$. Many factors contribute to a delayed diagnosis with the top-ranked issues being poor communication between secondary and primary care, a mismatch between patients' medical needs and health care supply, and a lack of access or use of health services $[42,44]$. For example, Behrbalk et al found that the average time delay from initiation of symptoms to the diagnosis of cervical spondylotic myelopathy (CSM) was 2.2 (SD 2.3) years [43]. Although symptom checkers can potentially address delayed diagnoses, a review showed that this technology was suboptimal in diagnosing CSM [30].

Moreover, these platforms generally provide a list of potential diagnoses rather than a single diagnosis. In this case, the user must decide which condition describes their current state best. The likelihood of a user to accurately choose the right diagnosis is associated with the sociodemographic profile/variables of a user, such as education and gender [33]. For example, women and those with higher education were more likely to choose the correct diagnosis [33]. Therefore, although having a timely diagnosis is important, it may be counterproductive if the user considers the wrong treatment options owing to a misdiagnosis. Moreover, the patient may still require a visit to a PCP to receive treatment or a prescription. Issues may arise if patients already have a diagnosis in mind when visiting their PCP as it could translate into disagreements regarding their condition.

This scoping review suggests that there are prominent knowledge gaps in the literature; as such, a systematic review may not be worthwhile on this topic. Rather, concerted efforts are needed in producing research in this area related to accuracy, user experience, regulation, doctor-patient relationship, PCP perspectives, and ethics. Specifically, extensive research is needed in evaluating the accuracy of this technology while accounting for the fact that some platforms are designed for a wide area of conditions and others are specialized-as such, these platforms need to be evaluated accordingly. It is also important to distinguish the difference between accuracy and correspondence with a PCP's diagnosis as PCPs may misdiagnose or miss a diagnosis [45-47]. Importantly, when developing self-diagnosing AI digital platforms, it is important to test them on users with a wide range of backgrounds and level of experience with technology. This will ensure that a high proportion of users will end up choosing the right diagnosis.

Along with the importance of accuracy in self-diagnosing applications, there also needs to be guidance on how these platforms should be regulated. Although regulations related to self-diagnosing AI technologies should focus on patient safety as well as privacy and security, they should not hinder innovation in this area; rather, they should allow innovative advancements that are safe and improve access to timely diagnosis. Overall, more knowledge is needed on how different types of users interact with this technology and how its use can impact the PCP-patient relationship. There is also a need for clarity on data management shared by users. Ethical concerns surrounding the digital economy is a main area of concern, and there is currently a debate surrounding the trade-offs pertaining to the use of these platforms.

\section{Limitations}

Some limitations of this scoping review warrant mention. Artificially intelligent self-diagnosing platforms that require individuals to upload an image or a scan were excluded from the review. Test kits or platforms that would require the user to perform medical tests were also excluded. Our scoping review's focus was on platforms that required the least amount of effort from the user (ie, simply entering their symptoms into the platform to obtain potential diagnoses). It is also possible that some potentially relevant articles were missed because they could not be retrieved. To counteract this limitation, the authors systematically reviewed the references of relevant articles and held multiple meetings to assess consistency and to discuss any discrepancies in the screening process.

\section{Conclusions}

Given self-diagnosing AI technology's potential, it is worth understanding how it can be leveraged by health care systems to reduce costs and unnecessary medical visits. This scoping review aimed to map the literature surrounding the use of artificially intelligent self-diagnosing platforms. Given the direct-to-consumer approach of these platforms, it is worrisome that only a few studies have focused on the use of this technology. It is important that future research and resources are directed to understanding the accuracy and regulation of self-diagnosing AI digital platforms. These regulations may take different forms such as creating an application library which includes a list of platforms that have been deemed safe and provide highly accurate diagnoses from a credible health agency or organization. It should be noted that patient engagement is necessary in the development of these platforms to ensure that they allow a high proportion of individuals-irrespective of gender and education-to choose the right diagnosis. Importantly, user experience is crucial to consider as the public may be skeptical of this technology.

\section{Acknowledgments}

The authors thank Rebecca Hutchinson, librarian at the University of Waterloo, for assisting in creating the search strategy. This study was funded by the Canadian Institutes of Health Research. The funder had no role in study design, study selection, data synthesis, decision to publish, or preparation of the manuscript. 


\section{Authors' Contributions}

SA conceived and designed the review. RHL, BND, AC, and SE participated in the conception of the study. SA, RHL, and BND carried out the review. All authors read and improved the final manuscript.

\section{Conflicts of Interest}

None declared.

\section{Multimedia Appendix 1}

Search strategy for PubMed (Medline).

[PDF File (Adobe PDF File), 57KB-Multimedia Appendix 1]

\section{Multimedia Appendix 2}

Overview of included studies related to self-diagnosing artificial intelligence digital platforms.

[PDF File (Adobe PDF File), 103KB-Multimedia Appendix 2]

\section{References}

1. Statistics Canada. 2009 Canadian Internet use survey URL: https://www150.statcan.gc.ca/n1/daily-quotidien/100510/ dq100510a-eng.htm [accessed 2019-04-06] [WebCite Cache ID 77RGfEkhd]

2. Beck F, Richard JB, Nguyen-Thanh V, Montagni I, Parizot I, Renahy E. Use of the internet as a health information resource among French young adults: results from a nationally representative survey. J Med Internet Res 2014;16(5):e128 [FREE Full text] [doi: 10.2196/jmir.2934] [Medline: 24824164]

3. Pew Research Centre. Health Online 2013 URL: https://www.pewinternet.org/2013/01/15/health-online-2013/ [accessed 2019-04-06] [WebCite Cache ID 77RGnsxqp]

4. Amante DJ, Hogan TP, Pagoto SL, English TM, Lapane KL. Access to care and use of the internet to search for health information: results from the US National Health Interview Survey. J Med Internet Res 2015;17(4):e106 [FREE Full text] [doi: 10.2196/jmir.4126] [Medline: 25925943]

5. Ybarra ML, Suman M. Help seeking behavior and the internet: a national survey. Int J Med Inform 2006 Jan;75(1):29-41. [doi: 10.1016/j.ijmedinf.2005.07.029] [Medline: 16129659]

6. Tonsaker T, Bartlett G, Trpkov C. Health information on the internet: gold mine or minefield? Can Fam Physician 2014 May;60(5):407-408 [FREE Full text] [Medline: 24828994]

7. Mosa AS, Yoo I, Sheets L. A systematic review of healthcare applications for smartphones. BMC Med Inform Decis Mak 2012;12:67 [FREE Full text] [doi: 10.1186/1472-6947-12-67] [Medline: 22781312]

8. Turing A. Computing machinery and intelligence. Mind 1950;49:433-460 [FREE Full text]

9. Senate Canada. Standing Senate Committee on Social Affairs, Science and Technology. 2017. Challenge ahead: Integrating Robotics, Artificial Intelligence and 3D Printing Technologies into Canada?s Healthcare Systems URL: https://sencanada. ca/content/sen/committee/421/SOCI/reports/RoboticsAI3DFinal Web e.pdf [accessed 2019-04-06] [WebCite Cache ID 77RH6QKQ0]

10. Semigran HL, Linder JA, Gidengil C, Mehrotra A. Evaluation of symptom checkers for self diagnosis and triage: audit study. Br Med J 2015;351:h3480 [FREE Full text] [Medline: 26157077]

11. Fraser H, Coiera E, Wong D. Safety of patient-facing digital symptom checkers. Lancet 2018 Dec 24;392(10161):2263-2264. [doi: 10.1016/S0140-6736(18)32819-8] [Medline: 30413281]

12. Millenson ML, Baldwin JL, Zipperer L, Singh H. Beyond Dr Google: the evidence on consumer-facing digital tools for diagnosis. Diagnosis (Berl) 2018 Dec 25;5(3):95-105. [doi: 10.1515/dx-2018-0009] [Medline: 30032130]

13. Business Insider. 2018. An AI startup that claimed it can beat doctors in an exam is putting $\$ 100$ million into creating 500 new jobs URL: https://www.businessinsider.com/babylon-health-invests-100-million-500-new-jobs-ai-research-2018-9 [accessed 2019-04-06] [WebCite Cache ID 77RH8Q52O]

14. Digital Health. 2018. Babylon goes to Canada with Telus Health partnership URL: https://www.digitalhealth.net/2018/09/ babylon-canadian-partnership/ [accessed 2019-04-06] [WebCite Cache ID 77RHHIlTb]

15. Brownlee S, Chalkidou K, Doust J, Elshaug AG, Glasziou P, Heath I, et al. Evidence for overuse of medical services around the world. Lancet 2017 Dec 08;390(10090):156-168 [FREE Full text] [doi: 10.1016/S0140-6736(16)32585-5] [Medline: $\underline{28077234]}$

16. Morgan DJ, Dhruva SS, Wright SM, Korenstein D. 2016 update on medical overuse: a systematic review. JAMA Intern Med 2016 Dec 01;176(11):1687-1692 [FREE Full text] [doi: 10.1001/jamainternmed.2016.5381] [Medline: 27654002]

17. Canadian Institute of Health Information. 2017. Unnecessary Care in Canada URL: https://www.cihi.ca/sites/default/files/ document/choosing-wisely-baseline-report-en-web.pdf [accessed 2019-04-06] [WebCite Cache ID 77RHLS5ur] 
18. Organisation for Economic Co-operation and Development. 2019. Health Care Quality Indicators URL: http://www.oecd.org/ health/health-systems/oecdhealthcarequalityindicatorsproject.htm [accessed 2019-04-06] [WebCite Cache ID 77RHoSJY9]

19. Tricco AC, Lillie E, Zarin W, O'Brien KK, Colquhoun H, Levac D, et al. PRISMA Extension for Scoping Reviews (PRISMA-ScR): Checklist and Explanation. Ann Intern Med 2018 Oct 02;169(7):467-473. [doi: 10.7326/M18-0850] [Medline: 30178033 ]

20. Haddaway NR, Collins AM, Coughlin D, Kirk S. The role of Google Scholar in evidence reviews and its applicability to grey literature searching. PLoS One 2015;10(9):e0138237 [FREE Full text] [doi: 10.1371/journal.pone.0138237] [Medline: 26379270]

21. Canadian Institutes of Health Research. 2016. A Guide to Knowledge Synthesis URL: http://www.cihr-irsc.gc.ca/e/29418. html [accessed 2019-04-06] [WebCite Cache ID 77RHreFWN]

22. McHugh ML. Interrater reliability: the kappa statistic. Biochem Med (Zagreb) 2012;22(3):276-282 [FREE Full text] [Medline: 23092060]

23. Wongpakaran N, Wongpakaran T, Wedding D, Gwet KL. A comparison of Cohen's kappa and Gwet's AC1 when calculating inter-rater reliability coefficients: a study conducted with personality disorder samples. BMC Med Res Methodol 2013;13:61 [FREE Full text] [doi: 10.1186/1471-2288-13-61] [Medline: 23627889]

24. Bauer M, Glenn T, Monteith S, Bauer R, Whybrow PC, Geddes J. Ethical perspectives on recommending digital technology for patients with mental illness. Int J Bipolar Disord 2017 Dec;5(1):6 [FREE Full text] [doi: 10.1186/s40345-017-0073-9] [Medline: 28155206]

25. Weldegebrial T. Marshall University, Department of Health Informatics. 2016. Regulations for eHealth \& mHealth Apps before Deployment URL: https://www.researchgate.net/publication/

318887422 Regulations for eHealth mHealth Apps before Deployment [accessed 2019-04-06] [WebCite Cache ID 77RI024W0]

26. Bisson LJ, Komm JT, Bernas GA, Fineberg MS, Marzo JM, Rauh MA, et al. Accuracy of a computer-based diagnostic program for ambulatory patients with knee pain. Am J Sports Med 2014 Oct;42(10):2371-2376. [doi: 10.1177/0363546514541654] [Medline: 25073597]

27. Bisson LJ, Komm JT, Bernas GA, Fineberg MS, Marzo JM, Rauh MA, et al. How accurate are patients at diagnosing the cause of their knee pain with the help of a web-based symptom checker? Orthop J Sports Med 2016 Feb;4(2):2325967116630286 [FREE Full text] [doi: 10.1177/2325967116630286] [Medline: 26962542]

28. Boulos MNK, Brewer AC, Karimkhani C, Buller DB, Dellavalle RP. Mobile medical and health apps: state of the art, concerns, regulatory control and certification. Online J Public Health Inform 2014;5(3):229 [FREE Full text] [doi: 10.5210/ojphi.v5i3.4814] [Medline: 24683442]

29. Copeland C, Morreale P, Li J. m-Health application Interface design for symptom checking. 2018 Presented at: 10th International Conference on e-Health; July 17-19, 2018; Madrid, Spain URL: http://tinyurl.com/y5jotoby

30. Davies BM, Munro CF, Kotter MR. A novel insight into the challenges of diagnosing degenerative cervical myelopathy using web-based symptom checkers. J Med Internet Res 2019 Jan 11;21(1):e10868 [FREE Full text] [doi: 10.2196/10868] [Medline: $\underline{\text { 30300137] }}$

31. Flaherty JL. Digital diagnosis: privacy and the regulation of mobile phone health applications. Am J Law Med 2014;40(4):416-441. [Medline: 27530051]

32. Farmer SE, Bernardotto M, Singh V. How good is internet self-diagnosis of ENT symptoms using Boots WebMD symptom checker? Clin Otolaryngol 2011 Oct;36(5):517-518. [doi: 10.1111/j.1749-4486.2011.02375.x] [Medline: 22032458]

33. Hageman MG, Anderson J, Blok R, Bossen JK, Ring D. Internet self-diagnosis in hand surgery. Hand (N Y) 2015 Sep;10(3):565-569 [FREE Full text] [doi: 10.1007/s11552-014-9707-x] [Medline: 26330798]

34. Jutel A, Lupton D. Digitizing diagnosis: a review of mobile applications in the diagnostic process. Diagnosis (Berl) 2015 Jun 01;2(2):89-96. [doi: 10.1515/dx-2014-0068] [Medline: 29540025]

35. Kao C, Liebovitz DM. Consumer mobile health apps: current state, barriers, and future directions. PM R 2017 May;9(5S):S106-S115. [doi: 10.1016/j.pmrj.2017.02.018] [Medline: 28527495]

36. Lanseng E, Andreassen T. Electronic healthcare: a study of people's readiness and attitude toward performing self - diagnosis. Int J of Service Industry Mgmt 2007 Aug 14;18(4):394-417. [doi: 10.1108/09564230710778155]

37. Luger TM, Houston TK, Suls J. Older adult experience of online diagnosis: results from a scenario-based think-aloud protocol. J Med Internet Res 2014 Jan 16;16(1):e16 [FREE Full text] [doi: 10.2196/jmir.2924] [Medline: 24434479]

38. Lupton D, Jutel A. 'It's like having a physician in your pocket!' A critical analysis of self-diagnosis smartphone apps. Soc Sci Med 2015 May;133:128-135. [doi: 10.1016/j.socscimed.2015.04.004] [Medline: 25864149]

39. Morita T, Rahman A, Hasegawa T, Ozaki A, Tanimoto T. The potential possibility of symptom checker. Int J Health Policy Manag 2017 Dec 05;6(10):615-616 [FREE Full text] [doi: 10.15171/ijhpm.2017.41] [Medline: 28949479]

40. Powley L, McIlroy G, Simons G, Raza K. Are online symptoms checkers useful for patients with inflammatory arthritis? BMC Musculoskelet Disord 2016 Dec 24;17(1):362 [FREE Full text] [doi: 10.1186/s12891-016-1189-2] [Medline: 27553253]

41. Ryan A, Wilson S. Internet healthcare: do self-diagnosis sites do more harm than good? Expert Opin Drug Saf 2008 May;7(3):227-229. [doi: 10.1517/14740338.7.3.227] [Medline: 18462181] 
42. Tudor Car L, Papachristou N, Bull A, Majeed A, Gallagher J, El-Khatib M, et al. Clinician-identified problems and solutions for delayed diagnosis in primary care: a PRIORITIZE study. BMC Fam Pract 2016 Dec 09;17:131 [FREE Full text] [doi: 10.1186/s12875-016-0530-z] [Medline: 27613564]

43. Behrbalk E, Salame K, Regev GJ, Keynan O, Boszczyk B, Lidar Z. Delayed diagnosis of cervical spondylotic myelopathy by primary care physicians. Neurosurg Focus 2013 Jul;35(1):E1. [doi: 10.3171/2013.3.FOCUS1374] [Medline: 23815245]

44. Aboueid S, Meyer SB. Factors affecting access and use of preventive and weight management care: A public health lens. Healthc Manage Forum 2019 Apr 03:840470418824345. [doi: 10.1177/0840470418824345] [Medline: 30943766]

45. Singh H, Schiff GD, Graber ML, Onakpoya I, Thompson MJ. The global burden of diagnostic errors in primary care. BMJ Qual Saf 2017 Jun;26(6):484-494 [FREE Full text] [doi: 10.1136/bmjqs-2016-005401] [Medline: 27530239]

46. Panesar SS, deSilva D, Carson-Stevens A, Cresswell KM, Salvilla SA, Slight SP, et al. How safe is primary care? A systematic review. BMJ Qual Saf 2016 Dec;25(7):544-553. [doi: 10.1136/bmjqs-2015-004178] [Medline: 26715764]

47. Nurek M, Kostopoulou O, Delaney BC, Esmail A. Reducing diagnostic errors in primary care. A systematic meta-review of computerized diagnostic decision support systems by the LINNEAUS collaboration on patient safety in primary care. Eur J Gen Pract 2015 Sep;21 Suppl:8-13 [FREE Full text] [doi: 10.3109/13814788.2015.1043123] [Medline: 26339829]

\title{
Abbreviations \\ AI: artificial intelligence \\ CSM: cervical spondylotic myelopathy \\ PCP: primary care provider
}

\author{
Edited by C Lovis; submitted 20.01.19; peer-reviewed by D Mendes, MS Aslam; comments to author 03.03.19; revised version received \\ 04.03.19; accepted 27.03.19; published 01.05.19 \\ Please cite as: \\ Aboueid S, Liu RH, Desta BN, Chaurasia A, Ebrahim S \\ The Use of Artificially Intelligent Self-Diagnosing Digital Platforms by the General Public: Scoping Review \\ JMIR Med Inform 2019;7(2):e13445 \\ URL: http://medinform.jmir.org/2019/2/e13445/ \\ doi: $\underline{10.2196 / 13445}$ \\ PMID: 31042151
}

(C) Stephanie Aboueid, Rebecca H Liu, Binyam Negussie Desta, Ashok Chaurasia, Shanil Ebrahim. Originally published in JMIR Medical Informatics (http://medinform.jmir.org), 01.05.2019. This is an open-access article distributed under the terms of the Creative Commons Attribution License (https://creativecommons.org/licenses/by/4.0/), which permits unrestricted use, distribution, and reproduction in any medium, provided the original work, first published in JMIR Medical Informatics, is properly cited. The complete bibliographic information, a link to the original publication on http://medinform.jmir.org/, as well as this copyright and license information must be included. 